ARTICLE

Received 22 Mar 2014 | Accepted 1 Sep 2014 | Published 6 Oct $2014 \quad$ DOl: 10.1038/ncomms6122

\title{
Aligned $\mathrm{Fe}_{2} \mathrm{TiO}_{5}$-containing nanotube arrays with low onset potential for visible-light water oxidation
}

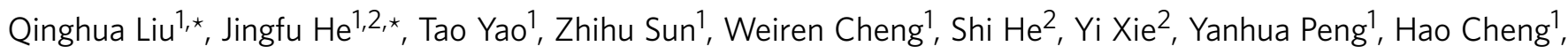
Yongfu Sun ${ }^{2}$, Yong Jiang ${ }^{1}$, Fengchun $\mathrm{Hu}^{1}$, Zhi Xie ${ }^{1}$, Wensheng Yan ${ }^{1}$, Zhiyun Pan ${ }^{1}$, Ziyu Wu${ }^{1} \&$ Shiqiang Wei ${ }^{1}$

There remains a pressing challenge in the efficient utilization of visible light in the photoelectrochemical applications of water splitting. Here, we design and fabricate pseudobrookite $\mathrm{Fe}_{2} \mathrm{TiO}_{5}$ ultrathin layers grown on vertically aligned $\mathrm{TiO}_{2}$ nanotube arrays that can enhance the conduction and utilization of photogenerated charge carriers. Our photoanodes are characterized by low onset potentials of $\sim 0.2 \mathrm{~V}$, high photon-to-current efficiencies of 40 $50 \%$ under $400-600 \mathrm{~nm}$ irradiation and total energy conversion efficiencies of $\sim 2.7 \%$. The high performance of $\mathrm{Fe}_{2} \mathrm{TiO}_{5}$ nanotube arrays can be attributed to the anisotropic charge carrier transportation and elongated charge carrier diffusion length (compared with those of conventional $\mathrm{TiO}_{2}$ or $\mathrm{Fe}_{2} \mathrm{O}_{3}$ photoanodes) based on electrochemical impedance analysis and first-principles calculations. The $\mathrm{Fe}_{2} \mathrm{TiO}_{5}$ nanotube arrays may open up more opportunities in the design of efficient and low-cost photoanodes working in visible light for photoelectrochemical applications.

\footnotetext{
${ }^{1}$ National Synchrotron Radiation Laboratory, University of Science and Technology of China, 42\# HeZuoHua Road, Hefei, Anhui 230029, China.

${ }^{2}$ Hefei National Laboratory for Physical Sciences at Microscale, University of Science and Technology of China, Hefei 230026, China. ${ }^{\star}$ These authors contributed equally to this work. Correspondence and requests for materials should be addressed to S.Q.W. (email: sqwei@ustc.edu.cn) or to Y.X. (email: yxie@ustc.edu.cn) or to Z.Y.W. (email: wuzy@ustc.edu.cn).
} 
$\mathrm{H}$ ow to find practical techniques for producing clean and sustainable energy is a globally demanding challenge due to the shortage of fossil fuels and global climate changes ${ }^{1,2}$. Especially, semiconductor photocatalysis has been widely studied as a promising method for converting sunlight into electricity or fuels and for purifying air and water ${ }^{3-5}$. The efficient solar-to-chemical energy conversion across a wide range of solar spectrum is believed to be important for practical uses of solar-driven clean energy systems ${ }^{6}$. However, for the most of stable metal oxides semiconductor photoanodes such as $\mathrm{TiO}_{2}$ and $\mathrm{ZnO}$, only ultraviolet light irradiation can be absorbed. Although some semiconductor photoanodes such as $\mathrm{Fe}_{2} \mathrm{O}_{3}$ were reported to be able to absorb visible lights, their photocarrier utilization for oxidizing water is relatively low and their quantum efficiencies are usually lower than $10 \%$ at $1.23 \mathrm{~V}$ versus reversible hydrogen electrode $(\mathrm{RHE})^{7,8}$. The architecture of vertically aligned nanotube arrays has shown considerate improvements to the quantum efficiencies of $\mathrm{TiO}_{2}$ and $\mathrm{Fe}_{2} \mathrm{O}_{3}$ photoanodes ${ }^{9-14}$, but the total conversion efficiency of visible lights is still not satisfactory. Therefore, it is highly desirable yet challenging to find an efficient photoanode semiconductor that is capable of using the abundant visible lights.

The key to maximize solar energy utilizations in photoanodes is the efficient separation and transportation of visible-lightinduced charge carriers in the water-splitting process. There are several remarkable factors that prevent the successful separation and transportation of charge carriers. First, for most of narrow bandgap metal oxide photoanodes, their conduction band minimum (CBM) positions are usually positive versus RHE. A large external electric field energy is therefore needed for the effective charge carrier separation and water-splitting reaction. Second, the depletion region is not long enough to separate the photoexcited carriers in the nanoscale photoanode, leading to a high recombination probability of photocarriers ${ }^{15}$. As a result, the photocarriers are localized within the photoelectrode interior and they can hardly migrate to surface water redox reaction sites ${ }^{16,17}$. All these factors significantly undermine the energy conversion efficiency under visible light illumination. Consequently, the development of new strategies that overcome the above limitations and the realization of efficient visible light conversion in narrow-bandgap semiconductor photoanodes are highly in demand.

In this work we report for the first time a pseudobrookite iron titanate $\mathrm{Fe}_{2} \mathrm{TiO}_{5}$ ultrathin layer supported on $\mathrm{TiO}_{2}$ nanotubearrayed photoanode for realizing highly efficient visible light conversion. $\mathrm{Fe}_{2} \mathrm{TiO}_{5}$ is a narrow bandgap semiconductor of $c a$. $2.2 \mathrm{eV}$ with the valence band edge surpassing the water oxidation level ${ }^{18}$. In particular, the $\mathrm{CBM}$ of $\mathrm{Fe}_{2} \mathrm{TiO}_{5}$ lies nearly at the same energy level as that of $\mathrm{TiO}_{2}$, leading to a quick onset of photocurrent under visible light irradiations. Moreover, the electronic and atomic structures of $\mathrm{Fe}_{2} \mathrm{TiO}_{5}$ match well with $\mathrm{TiO}_{2}$ and this would allow a good separation of the photogenerated hole carriers on the hybridized interface. In our design, the $\mathrm{Fe}_{2} \mathrm{TiO}_{5}$ layer is sandwiched between $\mathrm{TiO}_{2}$ and $\mathrm{Co}_{\text {ox }}$ layers $\left(\mathrm{Co}_{\text {ox }}\right.$ layer is coated as the surface catalyst $\left.{ }^{19,20}\right)$. We adopt the vertically self-organized nanotube array for this new photoanode, because it has the unique charge transport property and huge specific surface areas, by taking advantages of $\mathrm{Fe}_{2} \mathrm{TiO}_{5}$ and $\mathrm{TiO}_{2}$ layers with high catalytic efficiencies. The growth of the lattice-matched $\mathrm{Fe}_{2} \mathrm{TiO}_{5}$ on $\mathrm{TiO}_{2}$ is achieved by annealing the $\mathrm{TiO}_{2} / \mathrm{Fe}_{2} \mathrm{O}_{3}$ composite, where a solid-state reaction between $\mathrm{Fe}_{2} \mathrm{O}_{3}$ and $\mathrm{TiO}_{2}$ occured ${ }^{21}$. This closely contacting $\mathrm{Fe}_{2} \mathrm{TiO}_{5}$ composite nanotube array guarantees a substantial visible light absorption and introduces hole-electron separation interfaces required for fast separation and effective transportation of the electron-hole pairs. Therefore, our designed system is characterized by high quantum efficiencies (absorbed photon-tocurrent efficiency (APCE) $>40 \%$ ) under visible lights in the 400-600 nm wavelength range. It may also provide more insights to the optimization of photoelectrochemical performance of oxide semiconductor photoanodes.

\section{Results}

Structural identification. First of all, the as-designed composite photoanode is schematically presented in Fig. 1a-c. Figure $2 a-c$ show the scanning electron microscopy and transmission electron microscopy (TEM) of the system. It is evident that the nanotube arrays are well-aligned and perpendicular to the underlying substrate, with the tube length and wall thickness of about $7.8 \mu \mathrm{m}$ and $10 \mathrm{~nm}$, respectively. The morphology and performance of the $\mathrm{TiO}_{2}$ nanotube substrate were optimized before their modification (see Supplementary Figs 1 and 2, Supplementary Tables 1 and 2). The Fe-containing ultrathin layer can be clearly seen from an area of about $2-3 \mathrm{~nm}$ in width near the surface of the composite nanotubes in the high-resolution TEM image (Fig. $2 \mathrm{c}$ and Supplementary Figs 3 and 4). The grazing incidence X-ray diffraction patterns for the $\mathrm{TiO}_{2} / \mathrm{Fe}$-contained $/ \mathrm{Co}_{\text {ox }}$ sample suggest a main anatase structure (Fig. 2d). More importantly, new diffraction peaks at $26^{\circ}$ and $42^{\circ}$ are observed, which can be indexed to the (110) and (042) planes of pseudobrookite $\mathrm{Fe}_{2} \mathrm{TiO}_{5}$, respectively. Furthermore, the lattice space of $0.21 \mathrm{~nm}$ corresponding to (042) plane of orthorhombic $\mathrm{Fe}_{2} \mathrm{TiO}_{5}$ is observed from the high-resolution TEM image (Fig. 2c), in agreement with the selected area electron diffraction patterns (Supplementary Fig. 5). This can be further confirmed by the Raman spectra in Fig. 2e showing three peaks at 242, 297 and $410 \mathrm{~cm}^{-1}$, among which the $410 \mathrm{~cm}^{-1}$ peak is the strongest. These features correspond to the spectral characteristics of the iron titanate.

Fe $K$-edge X-ray absorption fine structure (XAFS) spectroscopy that is sensitive to the local environment around a specific atom ${ }^{22}$ is also employed to confirm the formation of $\mathrm{Fe}_{2} \mathrm{TiO}_{5}$ in the $\mathrm{TiO}_{2} / \mathrm{Fe}$-contained $/ \mathrm{Co}_{\text {ox }}$ nanotube arrays. First, the formation of $\mathrm{Fe}_{2} \mathrm{O}_{3}$ can be ruled out, as the $k^{3} \chi(k)$ oscillation shape and the corresponding Fourier transform (FT) curve (Fig. $2 \mathrm{f}$ and Supplementary Fig. 6) of the sample are quite different from that of $\mathrm{Fe}_{2} \mathrm{O}_{3}$. Moreover, the positions (around 2.55 and $3.21 \AA$ ) of $\mathrm{Fe}-\mathrm{Ti}$ coordination peaks in the FT curve of the sample are significantly lower than that of Ti-Ti1 and Ti-Ti2 peaks for $\mathrm{TiO}_{2}$, implying that the $\mathrm{Fe}$ atoms do not simply substitute for $\mathrm{Ti}$ in anatase $\mathrm{TiO}_{2}$. Furthermore, we show the FT spectrum at Fe Kedge for a reference compound $\mathrm{Fe}_{2} \mathrm{TiO}_{5}$ in Fig. 2f. It can be found that the three FT peaks of the $\mathrm{TiO}_{2} / \mathrm{Fe}$-contained $/ \mathrm{Co}_{\text {ox }}$ are well consistent with the spectrum of $\mathrm{Fe}_{2} \mathrm{TiO}_{5}$ reference, indicating that the $\mathrm{Fe}$-containing middle layer is truly in the form of the iron titanate $\mathrm{Fe}_{2} \mathrm{TiO}_{5}$. Moreover, the nominal thickness of Co layer is estimated as $0.5-1.0 \mathrm{~nm}$, and Co $K$-edge XAFS measurements confirm the presence of short-range six-coordinated Co-based catalyst $\left(\mathrm{Co}_{\mathrm{ox}}\right)$ on the surface of $\mathrm{Fe}_{2} \mathrm{TiO}_{5}-\mathrm{TiO}_{2}$ (Supplementary Fig. 7).

Photoelectrochemical performance. To investigate the photoelectrochemical performances of the $\mathrm{Fe}_{2} \mathrm{TiO}_{5}-\mathrm{TiO}_{2} / \mathrm{Co}_{\text {ox }}$ nanotube-arrayed architecture, its quantum efficiency was measured and shown in Fig. 3a. For reference, the efficiencies of $\mathrm{TiO}_{2}, \mathrm{TiO}_{2} /$ $\mathrm{Co}_{\text {ox }}$ and $\mathrm{Fe}_{2} \mathrm{O}_{3}$ nanotube-arrayed photoanodes are also displayed. The incident photon-to-current efficiency (IPCE, see Fig. $3 \mathrm{a}$ and Supplementary Note 1) curve shows that the $\mathrm{Fe}_{2} \mathrm{TiO}_{5^{-}}$ $\mathrm{TiO}_{2} / \mathrm{Co}_{\mathrm{ox}}$ nanotube array-based photoanode possesses a high IPCE of about $40 \%$ at the visible light wavelength of $475 \mathrm{~nm}$, and it remains robust at longer wavelength (over $10 \%$ at $620 \mathrm{~nm}$ ). In contrast, the efficiencies of both of the pristine $\mathrm{TiO}_{2}-$ and 
a

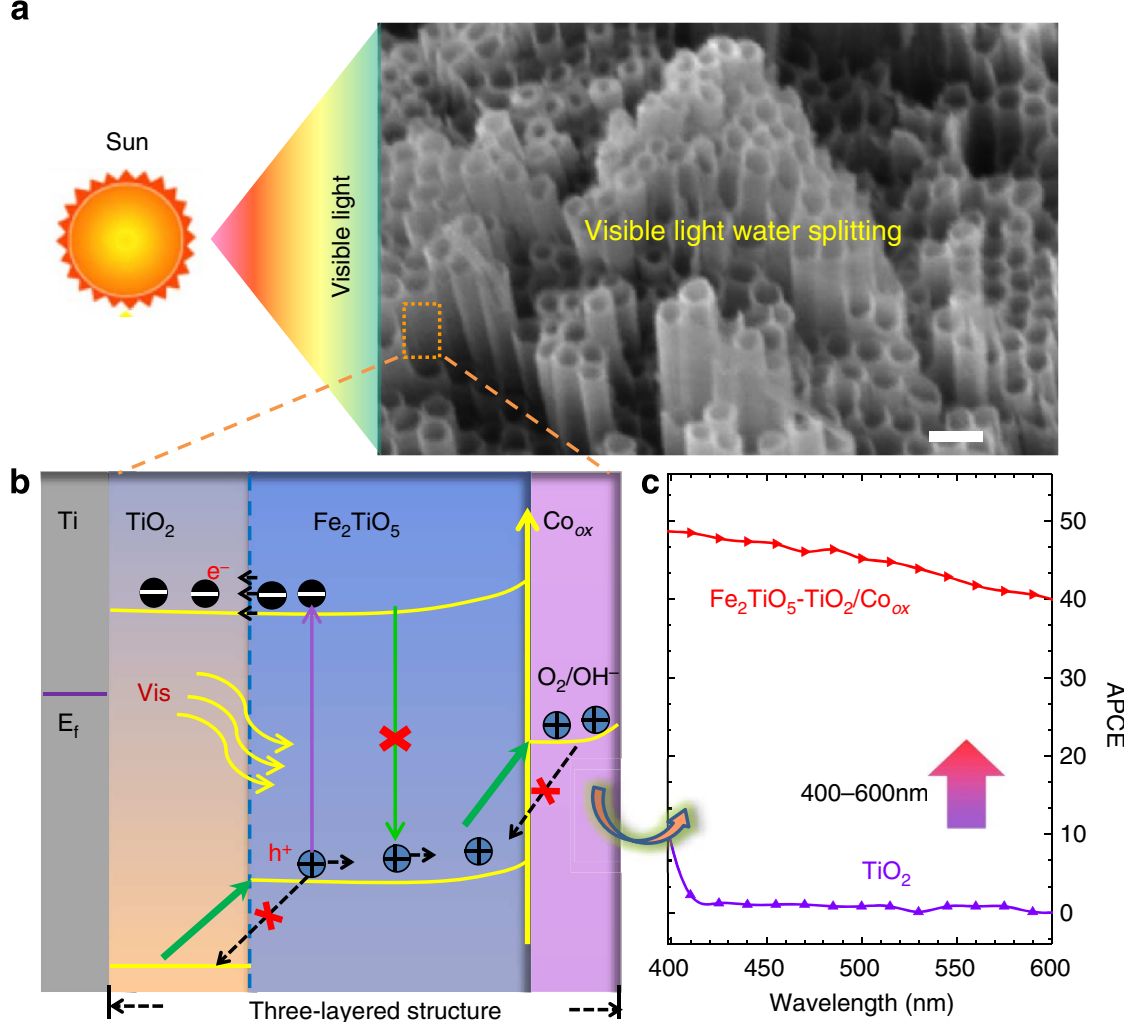

Figure 1 | Photoanode architecture and photoelectrochemical reaction mechanism. (a) Schematic of the sunlight irradiation on the composite $\mathrm{Fe}_{2} \mathrm{TiO}_{5}-\mathrm{TiO}_{2} / \mathrm{Co}_{\text {ox }}$ nanotube-arrayed photoanode. Scale bar, $200 \mathrm{~nm}$. (b) Schematic of the composite photoanode architecture and solar water oxidation mechanism, and (c) the resulting quantum efficiency of the photoanode. $E_{\mathrm{f}}$, Fermi level. The model only represents the idealized electronic structure alignment of the composite photoanode.
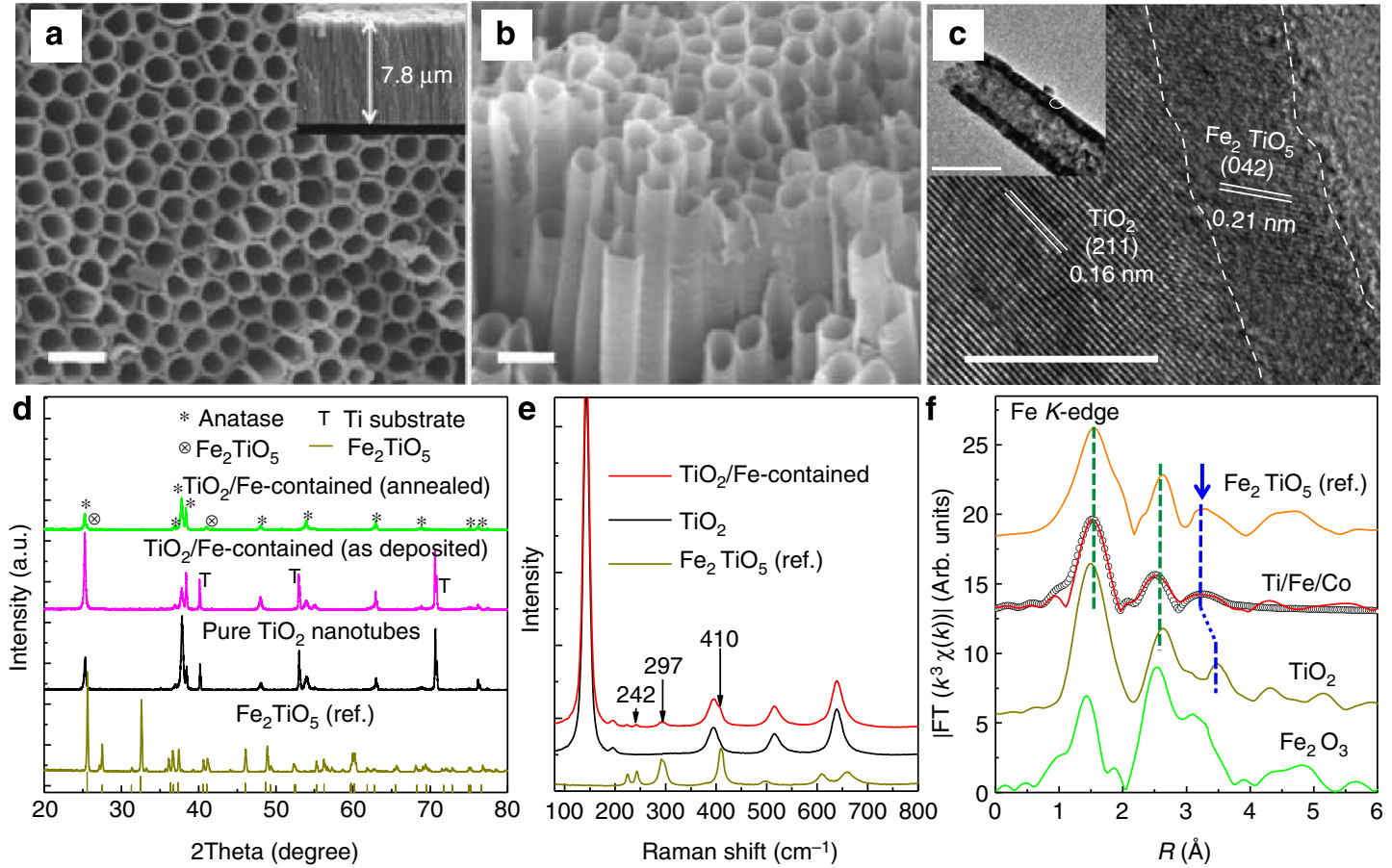

Figure 2 | Morphology and structural properties of the samples. (a,b) Scanning electron microscopy and and (c) high-resolution TEM images for $\mathrm{TiO}_{2} / \mathrm{Fe}$-contained $/ \mathrm{Co}_{\text {ox }}$ nanotube arrays. Scale bars, 200, 200, 5 and $100 \mathrm{~nm},(\mathbf{a}, \mathbf{b}, \mathbf{c}$ and inset of $\mathbf{c}$, respectively). (d) X-ray diffraction patterns for pure $\mathrm{TiO}_{2}, \mathrm{Fe}_{2} \mathrm{TiO}_{5}$ reference sample and as-deposited $\mathrm{TiO}_{2} / \mathrm{Fe}$-contained nanotube arrays, and grazing incidence $\mathrm{X}$-ray diffraction patterns for the annealed $\mathrm{TiO}_{2} / \mathrm{Fe}$-contained nanotube arrays. The standard card (PCPDF 76-1158) for orthorhombic $\mathrm{Fe}_{2} \mathrm{TiO}_{5}$ is shown for reference. (e) Raman spectra for TiO $\mathrm{TiO}_{2} / \mathrm{Fe}$-contained nanotube-arrayed photoanodes and reference $\mathrm{Fe}_{2} \mathrm{TiO}_{5}$ (ref.). (f) Fe $K$-edge EXAFS FTs of $k^{3} \chi(k)$ functions for TiO $/ \mathrm{Fe}-\mathrm{contained} / \mathrm{Co}_{\text {ox }}$. The empty circles show the fitting results. The $\mathrm{Fe} K$-edge spectra for $\mathrm{Fe}_{2} \mathrm{O}_{3}$ and $\mathrm{Ti} K$-edge spectra for $\mathrm{TiO}_{2}$ and $\mathrm{Fe}_{2} \mathrm{TiO}_{5}\left(\mathrm{ref}_{\text {.) }}\right.$ are shown for comparison. The reference $\mathrm{Fe}_{2} \mathrm{TiO}_{5}$ (ref.) sample in $\mathbf{d}, \mathbf{e}$ and $\mathbf{f}$ was synthesized by solid-state reaction method. 
a
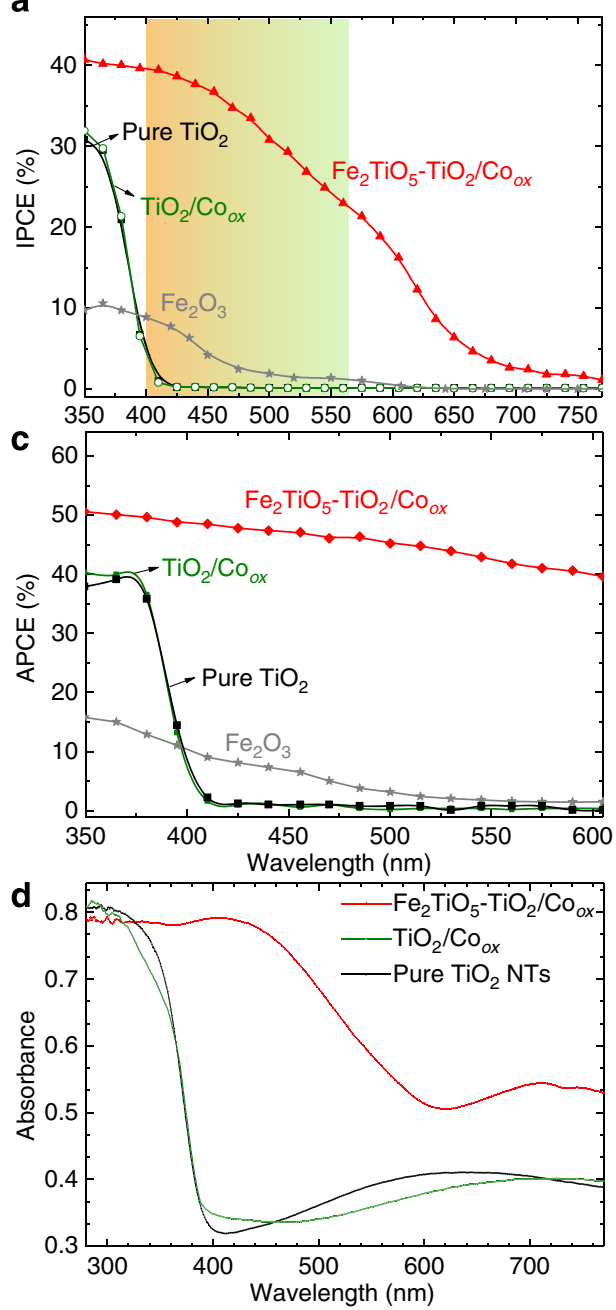

b
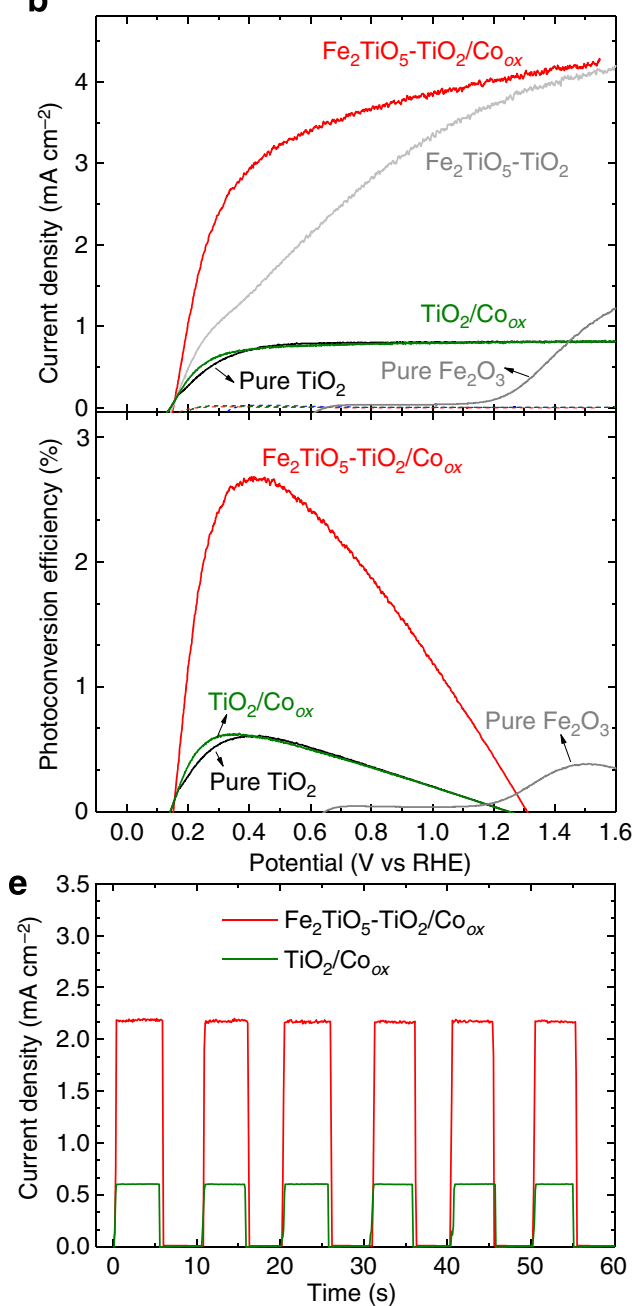

Figure 3 | Optical absorption and photoelectrochemical performance of the samples. (a) IPCE curves (measured at $0.4 \mathrm{~V}$ versus $\mathrm{RHE}_{\mathrm{H}}$ for pure $\mathrm{TiO}$, $\mathrm{TiO}_{2} / \mathrm{Co}_{\text {ox }}$ and $\mathrm{Fe}_{2} \mathrm{TiO}_{5}-\mathrm{TiO}_{2} / \mathrm{Co}_{\text {ox }}$ and at $1.23 \mathrm{~V}$ versus $\mathrm{RHE}$ for $\mathrm{Fe}_{2} \mathrm{O}_{3}$ ). (b) Upper panel: dark current (dash lines) and photocurrent (solid lines) densities; lower panel: photoconversion efficiencies. (c) APCE curves of pure $\mathrm{TiO}_{2}, \mathrm{TiO}_{2} / \mathrm{Co}_{\text {ox }}, \mathrm{Fe}_{2} \mathrm{TiO}_{5}-\mathrm{TiO}_{2} / \mathrm{Co}_{\text {ox }}$ and $\mathrm{Fe}_{2} \mathrm{O}_{3}$ photoanodes in $1 \mathrm{M} \mathrm{KOH}$. (d) Ultraviolet-visible spectra of pure $\mathrm{TiO}_{2}, \mathrm{TiO}_{2} / \mathrm{Co}_{\text {ox }}$ and $\mathrm{Fe}_{2} \mathrm{TiO}_{5}-\mathrm{TiO}_{2} / \mathrm{Co}_{\text {ox }}$ samples. (e) Transient photocurrent curves for $\mathrm{TiO}_{2} / \mathrm{Co}_{\text {ox }}$ and $\mathrm{Fe}_{2} \mathrm{TiO}_{5}-\mathrm{TiO}_{2} /$ $\mathrm{Co}_{\text {ox }}$ photoanodes performed with chopped light at $0.3 \mathrm{~V}$ versus $\mathrm{RHE}$ in $1 \mathrm{M} \mathrm{KOH}$.

$\mathrm{Co}_{\text {ox }}$-coated nanotubes are similar and extremely low, and $\mathrm{Fe}_{2} \mathrm{O}_{3}$ nanotube (Fig. 3 and Supplementary Figs 8 and 9) also has a low photon-to-current efficiency of $<10 \%$, which is in consistence with previous reports ${ }^{23}$. Figure $3 \mathrm{~b}$ shows a high current density of $4.1 \mathrm{~mA} \mathrm{~cm}{ }^{-2}$ for the $\mathrm{Fe}_{2} \mathrm{TiO}_{5}-\mathrm{TiO}_{2} / \mathrm{Co}_{\text {ox }}$ photoanode at $1.23 \mathrm{~V}$ versus RHE. In particular, the photocurrent onset potential of $0.18 \mathrm{~V}$ versus RHE corresponds to a small external bias of $0.2 \mathrm{~V}$, which is significantly lower than that of narrow-bandgap $\mathrm{Fe}_{2} \mathrm{O}_{3}$ $\left(\sim 1.0 \mathrm{~V}\right.$ for pristine $\mathrm{Fe}_{2} \mathrm{O}_{3}$ and $\sim 0.7 \mathrm{~V}$ for $\mathrm{Fe}_{2} \mathrm{O}_{3}$ modified with cocatalyst), resulting in a large total photoconversion efficiency of $2.7 \%$ (Fig. 3b and Supplementary Note 2). The photocurrent is almost not degraded within $2 \mathrm{~h}$ (Supplementary Figs 10 and 11), confirming the photoelectrochemical stability of the composite photoanode architecture. The saturated photocurrent of the composite photoanode is able to reach $4.2 \mathrm{~mA} \mathrm{~cm}^{-2}$, which is comparable to that of recent $\mathrm{FeOOH} / \mathrm{NiOOH}$ dual layer modified nanoporous $\mathrm{BiVO}_{4}$ photoanode ${ }^{24}$ and is noticeably higher than those of using pure metal oxides as visible light photon absorber ${ }^{25-27}$.

The APCE curves in Fig. 3c show that a highly efficient visible photoelectrochemical conversion with large quantum efficiencies has been realized when $\mathrm{Fe}_{2} \mathrm{TiO}_{5}$ is incorporated in the nanotube- arrayed photoanode (Supplementary Note 3). Moreover, the quantum efficiencies keep almost steady at a high level (45-50\%) in the whole absorption range. Moreover, the $\mathrm{Fe}_{2} \mathrm{TiO}_{5}$-containing nanotube arrays with the length up to several micrometres ensure a substantial visible light absorption (Fig. 3d). Hence, our deliberately designed composite structure successfully overcomes low quantum efficiency limits of only a few per cent for transforming deep-visible photons to current by pristine oxide semiconductor photoanodes. In addition, the $\mathrm{Fe}_{2} \mathrm{TiO}_{5}$-containing photoanode combines the advantages of substantial optical absorption of narrow-bandgap $\mathrm{Fe}_{2} \mathrm{O}_{3}$ and a low external bias of wide-bandgap $\mathrm{TiO}_{2}$ to drive solar water oxidation. Together with the intrinsic merits of anticorrosion and cheapness of transition metal oxides, this composite system has shown its great potential as a practical photoelectrochemical material ${ }^{28}$.

\section{Discussion}

For a typical compact n-type semiconductor thin film photoanode, the magnitude of photocurrent corresponds to the number of photogenerated holes that react on the electrode surface. In general, it is determined by the competition of carriers migration 

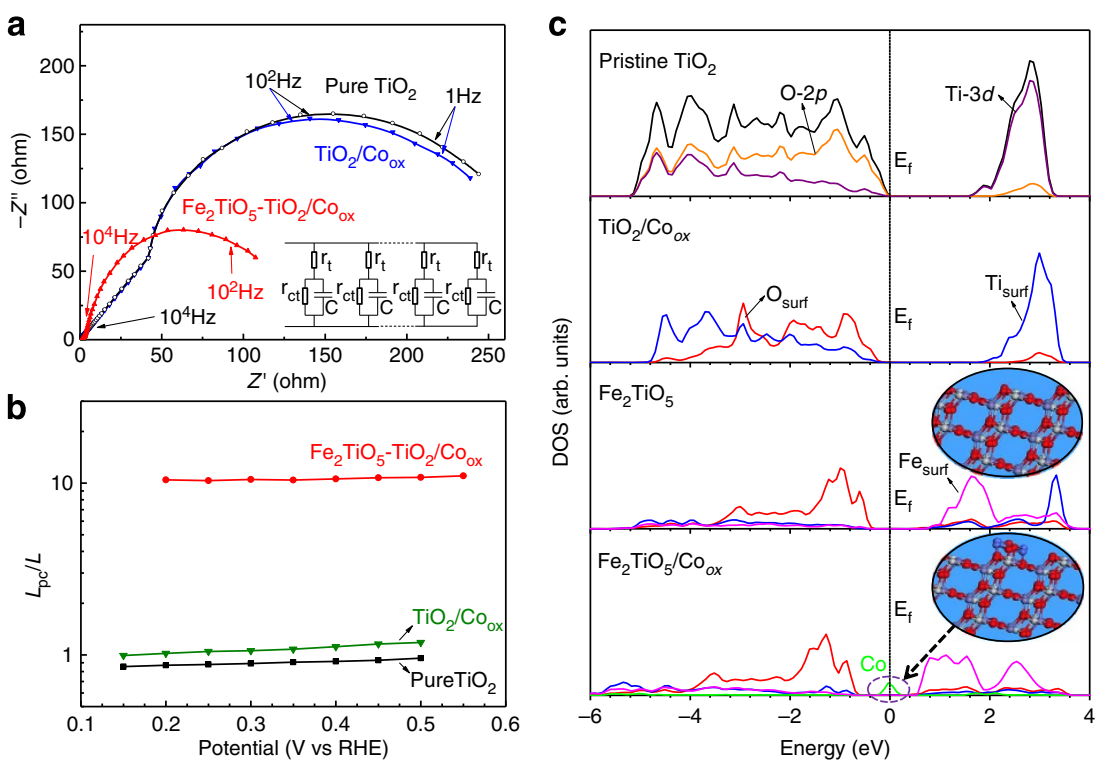

Figure 4 | Electrochemical impedance properties and electronic structure modelling. (a) Electrochemical impedance spectra measured for the samples, $Z^{\prime}$ and $Z^{\prime \prime}$ are the real and imaginary parts of impedance. The inset shows the equivalent circuit. (b) Calculated carrier diffusion lengths for the pristine $\mathrm{TiO}_{2}$, $\mathrm{TiO}_{2} / \mathrm{Co}_{\text {ox }}$ and $\mathrm{Fe}_{2} \mathrm{TiO}_{5}-\mathrm{TiO}_{2} / \mathrm{Co}_{\text {ox }}$ nanotube films. (c) Calculated electronic structures for pristine $\mathrm{TiO}_{2}, \mathrm{TiO}_{2} / \mathrm{Co}_{\text {ox }}$ and $\mathrm{Fe}_{2} \mathrm{TiO}_{5}-\mathrm{TiO}_{2} / \mathrm{Co}_{\text {ox }}$ models. The insets show the model structures used for calculations.

and recombination ${ }^{29}$. To further investigate this competition in the $\mathrm{Fe}_{2} \mathrm{TiO}_{5}-\mathrm{TiO}_{2}$ photoanode, the energy band positions are first analysed under scrutiny. Mott-Schottky plot and $J^{2} \propto\left(V-V_{\mathrm{fb}}\right)$ relationship are usually used to identify the CBM position of n-type semiconductor electrode. As shown in Supplementary Fig. 12, the flat band potentials of $\mathrm{TiO}_{2}$ and $\mathrm{Fe}_{2} \mathrm{TiO}_{5}$ are within $0.05 \mathrm{~V}$ difference and located at about 0.18 and $0.23 \mathrm{~V}$ versus RHE, respectively. Thus, the CBM positions are about $0 \mathrm{~V}$ versus RHE, which ensures the electron exchange between the two components. Considering the bandgap energy from the ultraviolet-visible absorption spectra, it is concluded that the valence band maximum (VBM) position of $\mathrm{Fe}_{2} \mathrm{TiO}_{5}$ is about $1.0 \mathrm{eV}$ above that of $\mathrm{TiO}_{2}$. The energy level of Co-layer catalyst identified as the redox potential is about $1.6 \mathrm{~V}$ versus RHE (Supplementary Fig. 13). As a result, a gradient band structure forms, in which the interface between $\mathrm{Fe}_{2} \mathrm{TiO}_{5} / \mathrm{TiO}_{2}$ makes the photoholes only transfer from the valence bands of $\mathrm{Fe}_{2} \mathrm{TiO}_{5}$ to $\mathrm{Co}_{\text {ox }}$, while the electrons can migrate from the conduction bands of $\mathrm{Fe}_{2} \mathrm{TiO}_{5}$ to $\mathrm{TiO}_{2}$ (Fig. 1b). Meanwhile, the interface of $\mathrm{Fe}_{2} \mathrm{TiO}_{5} / \mathrm{Co}_{\text {ox }}$ could timely trap the holes and transfer them onto the surface active sites because of its strong ability of absorbing holes. Hence, the hole-electron separation interface introduced by $\mathrm{Fe}_{2} \mathrm{TiO}_{5}$ can well direct the transfer of hole carriers through the vectorial hole-transfer channel to reach the tube wall (Fig. 1 and Supplementary Fig. 14). Indeed, the energy gradient of molecular orbitals can regulate charge transfer path on the molecular and semiconductor interface of dye-sensitized solar cells ${ }^{30}$. This $\mathrm{Fe}_{2} \mathrm{TiO}_{5}$-containing composite nanotube structure could alter the competition of carriers migration and recombination in two aspects: (1) the visible-light-generated holes are within $2 \mathrm{~nm}$ distance from the tube wall, which greatly shortens the diffusion layer width $(L)$; and (2) the quick separation of holes and electrons from $\mathrm{Fe}_{2} \mathrm{TiO}_{5} / \mathrm{TiO}_{2}$ interface could increase the photocarriers lifetime and diffusion length $\left(L_{\mathrm{pc}}\right)$. From the APCE results in Figs $1 \mathrm{c}$ and $3 \mathrm{c}$, it can be seen that the photons with wavelength of $620 \mathrm{~nm}$ (close to the absorption edge for $\mathrm{Fe}_{2} \mathrm{TiO}_{5}-\mathrm{TiO}_{2} / \mathrm{Co}_{\text {ox }}$ ) could be effectively converted. In contrast, the effective photon-to-current conversion wavelength for pristine $\mathrm{Fe}_{2} \mathrm{O}_{3}$ is up to about $500 \mathrm{~nm}$, corresponding to an energy lower than the absorption edge of $\mathrm{Fe}_{2} \mathrm{O}_{3}$. This is presumably due to the inefficient separation and transportation of the low-energy carriers excited by the high-wavelength photons near the absorption edge ${ }^{31}$. Our quantum efficiency measurement for pristine $\mathrm{Fe}_{2} \mathrm{O}_{3}$ nanotube photoanode is performed under $1.23 \mathrm{~V}$ versus RHE. It was reported that at a higher applied potential of $1.53 \mathrm{~V}$ versus RHE, the IPCE value of nanostructured $\mathrm{Fe}_{2} \mathrm{O}_{3}$ photoanodes can increase to $45 \%$ in the $300-450 \mathrm{~nm}$ wavelength range ${ }^{32}$. Another point to note is that the performance of the composite structure is gradually decreased with increasing thickness of $\mathrm{Fe}_{2} \mathrm{TiO}_{5}$ layer (Supplementary Fig. 15). This suggests that the carrier-transport-guide effect of the hole-electron separation interface is significantly affected as the thickness of $\mathrm{Fe}_{2} \mathrm{TiO}_{5}$ layer approaches the diffusion length, which is presumably responsible for the low photoelectrochemical performance of bulk $\mathrm{Fe}_{2} \mathrm{TiO}_{5}$ photocatalyst ${ }^{33}$. On the other hand, decreasing the $\mathrm{Fe}_{2} \mathrm{TiO}_{5}$ layer thickness would reduce the optical absorption. Therefore, the nominal $2 \mathrm{~nm}$ thickness of $\mathrm{Fe}_{2} \mathrm{TiO}_{5}$ layer is optimized for achieving maximum visible-light conversion efficiency via the hole-electron separation interface.

To validate the impact of vectorial hole-transfer channel on $L$ and $L_{\mathrm{pc}}$, the electrochemical impedance spectroscopy (EIS) measurements are performed and shown in Fig. 4a. For nanostructure electrode with particle size sufficiently small $(<10 \mathrm{~nm})$, electromigration from band bending is likely to be negligible and transmission line model of EIS is suitable to evaluate the charge diffusion characteristics ${ }^{34,35}$. However, for the nanotube morphology electrode it becomes more complicated, as the geometry can be viewed as a combination of the characteristic nanostructure size in the radial direction with a macroscopic continuous pathway in the axial direction. Moreover, it is obvious that the diffusion photocurrent would be dominant (Supplementary Fig. 16), which is also indicated by the large photocurrent of $\mathrm{Fe}_{2} \mathrm{TiO}_{5}-\mathrm{TiO}_{2} / \mathrm{Co}_{\text {ox }}$ at the flat band potential. Based on these facts, an equivalent circuit has been developed and displayed in the inset of Fig. 3a, where the series resistance represents the charge carrier diffusion along the axial direction, while the parallel resistance stands for the charge carrier diffusion along the radial direction (Supplementary Note 4 and 
Supplementary Fig. 17). It can be found that the transmission impedance is significantly reduced, probably because the weight of equivalent circuits is transferred from series connection to parallel connection. The $L_{\mathrm{pc}} / L$ increases by more than ten times compared with that of $\mathrm{TiO}_{2}$ (Fig. 4b) and $\mathrm{Fe}_{2} \mathrm{O}_{3}$ (Supplementary Fig. 18), when the $\mathrm{Fe}_{2} \mathrm{TiO}_{5}$ layer is introduced in the nanotubes. These results indicate an enhanced charge carrier transfer ability in the composite structure (Fig. 1b), which is due to the carrier separation interface of $\mathrm{Fe}_{2} \mathrm{TiO}_{5} / \mathrm{TiO}_{2}$ that has successfully separated the electrons and holes to the different diffusion regions of $\mathrm{TiO}_{2}$ layer and $\mathrm{Fe}_{2} \mathrm{TiO}_{5}$ layer, respectively. This leads to a maximized gradient of carrier distribution and results in the regulated carriers distribution and the prolonged carriers lifetime. Moreover, the transient photocurrent measurements in Fig. 3e show that the steady-state photocurrent densities of $\mathrm{Fe}_{2} \mathrm{TiO}_{5^{-}}$ $\mathrm{TiO}_{2} / \mathrm{Co}_{\text {ox }}$ photoanode are significantly enhanced relative to those of parent $\mathrm{TiO}_{2}$-based photoanodes. Evidently, there are no spikes within the first second of irradiation in the transient photocurrent spectrum of $\mathrm{Fe}_{2} \mathrm{TiO}_{5}-\mathrm{TiO}_{2} / \mathrm{Co}_{\text {ox }}$, suggesting that the hole transfer bottlenecks from the interior to outside of $\mathrm{Fe}_{2} \mathrm{TiO}_{5}-\mathrm{TiO}_{2} / \mathrm{Co}_{\text {ox }}$ nanotubes is resolved ${ }^{36}$. Hence, these results demonstrate an anisotropic charge carrier transfer character in the composite structure, which is further confirmed by the sequential injection of negative charges by the overlayer (Supplementary Note 5). Benefiting from the vectorial holetransfer channel, an effective collection of charge carriers excited by the visible light is realized in the composite structure.

The oxidation activity of the holes that transport to surface is intimately related to the electronic structure of the surface states. Figure $4 \mathrm{c}$ shows the calculated density of states for the different structural configurations. For pristine $\mathrm{TiO}_{2}$ and $\mathrm{Fe}_{2} \mathrm{TiO}_{5}$, the Fermi level locates in the middle of the vacant bandgap, in line with the band structure character of ideal semiconductor. It can be seen that the $\mathrm{Co}_{\text {ox }}$ can hardly change the energy states of surface $\mathrm{Ti}\left(\mathrm{Ti}_{\text {surf }}\right)$ and $\mathrm{O}\left(\mathrm{O}_{\text {surf }}\right)$ atoms of $\mathrm{TiO}_{2}$ (see the second panel of Fig. 4c). However, as $\mathrm{Co}_{\text {ox }}$ coupled with $\mathrm{Fe}_{2} \mathrm{TiO}_{5}$, a gap state across the Fermi level is formed, because of the interaction between the $\mathrm{Co}_{\text {ox }}$ (green curve) and surface $\mathrm{O}$ (red curve) atoms as shown in the bottom panel of Fig. 4c. The gradient energy level of the highest occupied energy state confirms the vectorial transfer of charges in the nanotube. Meanwhile, a half-empty energy band of $\mathrm{Co}_{\mathrm{ox}}$ is formed in the gap (denoted by the arrow in Fig. 4c). Speaking in general, the catalytic activity of photoanode is strongly dependent on the property of surface energy states, especially the $d$ orbital states that directly participate in the water redox reaction ${ }^{37}$. The half-empty energy state of surface $\mathrm{O}$ and Co can strongly increase the binding of the initial product $\mathrm{OH}$ of water splitting and overcome the reaction barrier, resulting in an enrichment of $\mathrm{OH}$ on the $\mathrm{Fe}_{2} \mathrm{TiO}_{5} / \mathrm{Co}_{\text {ox }}$ surface. This makes the required bias of $\mathrm{Fe}_{2} \mathrm{TiO}_{5} /$ $\mathrm{Co}_{\text {ox }}$ surface for water cleavage reduce to $200 \mathrm{mV}$, which matches well with the hole energy of $\mathrm{Fe}_{2} \mathrm{TiO}_{5}$. It is worth noting that for $\mathrm{Fe}_{2} \mathrm{TiO}_{5}-\mathrm{TiO}_{2}$ nanotube arrays, the VBM position is upshifted by $1.0 \mathrm{eV}$ compared with pure $\mathrm{TiO}_{2}$. The overpotential of photogenerated holes at the VBM is then greatly decreased and thus it is not sufficient for the water oxidation, which is confirmed by the photocurrent curve of $\mathrm{Fe}_{2} \mathrm{TiO} 5-\mathrm{TiO}_{2}$ in Fig. 3b. The photocurrent value of $\mathrm{Fe}_{2} \mathrm{TiO}_{5}-\mathrm{TiO}_{2}$ approaches that of $\mathrm{Fe}_{2} \mathrm{TiO}_{5^{-}}$ $\mathrm{TiO}_{2} / \mathrm{Co}_{\text {ox }}$ at higher overpotential, indicating a similar diffusion efficiency (Supplementary Discussion). In addition to the highly efficient hole transfer via the vectorial hole-transfer channel, both ultraviolet and visible light excited holes can efficiently catalyse water oxidation through the $\mathrm{Co}_{\mathrm{ox}}$ catalyst.

In summary, we develop a simple strategy to fabricate a new pseudobrookite $\mathrm{Fe}_{2} \mathrm{TiO}_{5}$ material deposited on the vertically oriented $\mathrm{TiO}_{2}$ nanotube arrays, for the efficient separation and transportation of low-energy visible-light-excited charge carriers. The grazing incidence X-ray diffraction, Raman and XAFS techniques indicate the formation of $\mathrm{Fe}_{2} \mathrm{TiO}_{5}$ layers on the $\mathrm{TiO}_{2}$ nanotube arrays. The quantum efficiency measurements demonstrate that this $\mathrm{Fe}_{2} \mathrm{TiO}_{5}$-containing nanotube arrays with a low onset potential of $\sim 0.2 \mathrm{~V}$ exhibit a sustainably high quantum efficiency of $>40 \%$ from ultraviolet to $600 \mathrm{~nm}$ with a total energy conversion efficiency of $2.7 \%$. Combining ultraviolet-visible absorption, EIS and first-principles density functional theory calculations, the high visible photoelectrochemical performance of this composite structure can be attributed to the anisotropic charge carrier transport and reduced charge carrier transfer resistance. Moreover, the vertically aligned nanotube arrays with huge specific surface areas and superior transport property offer a well-behaving architecture, which in turn promotes the transfer of the visible-light-excited photoholes to the photocatalyst surface to participate in water redox reactions. By extending the optical absorption towards far visible regions, the overall photoelectrochemical efficiencies of these processes and/or devices are expected to be further enhanced. To overcome the deficiency of back-side illumination on the photoelectrode, the base of $\mathrm{TiO}_{2}$ nanotube arrays grown on fluorine-doped tin oxide glass substrate has been proposed ${ }^{38}$, where more efficient front-side illumination could be realized. Our design may open up opportunities to modify the semiconductor oxides towards high photoconversion efficiency for practical photochemical applications.

\section{Methods}

Materials. Titanium foil $(0.25 \mathrm{~mm}$ thickness, $99.99 \%$ trace metals basis, Aldrich) was used for electrochemical anodization. Ethylene glycol, ammonium fluoride, ferric nitrate, cobalt nitrate and potassium phosphate (all from Aldrich) were used as precursors.

Synthesis of $\mathrm{TiO}_{\mathbf{2}}$ nanotube-arrayed photoanodes. The $\mathrm{Fe}_{2} \mathrm{TiO}_{5}$ layer supported on the highly ordered $\mathrm{TiO}_{2}$ nanotube arrays was prepared by an electrochemical deposition in combination with post-annealing method. First, the $\mathrm{TiO}_{2}$ nanotube arrays were prepared by the electrochemical anodization in a $\mathrm{NH}_{4} \mathrm{~F}$ organic electrolyte with optimized performance. Briefly, the pure titanium foils were ultrasonically cleaned with acetone, ethanol and deionized water, followed by drying under a nitrogen stream. Then, the Ti foils were immersed in a mixed ethylene glycol solution of 0.35 wt.\% $\mathrm{NH}_{4} \mathrm{~F}$ and 2 vol.\% deionized water, and subjected to a constant potential $(60 \mathrm{~V})$ at room temperature in a two-electrode configuration with titanium foil as the working electrode and platinum mesh as the counter electrode. An $\mathrm{Fe}_{2} \mathrm{O}_{3}$ layer was subsequently electrodeposited onto $\mathrm{TiO}_{2}$ nanotubular array film in a $5-\mathrm{mM} \mathrm{Fe}\left(\mathrm{NO}_{3}\right)_{3}$ solution at $-0.6 \mathrm{~V}$ versus $\mathrm{AgCl} / \mathrm{Ag}$. Then, the heterojunction products were annealed at $550{ }^{\circ} \mathrm{C}$ for $2 \mathrm{~h}$ in ambient air to obtain $\mathrm{Fe}_{2} \mathrm{TiO}_{5} / \mathrm{TiO}_{2}$ composite bilayer. For the $\mathrm{Co}_{\text {ox }}$ deposition, the photoanode was submerged in an electrolyte solution of $25 \mathrm{mM} \mathrm{Co}\left(\mathrm{NO}_{3}\right)_{2}$ in $0.1 \mathrm{M} \mathrm{K}_{2} \mathrm{SO}_{4}$ (pH 7.0) and a bias of $1.6 \mathrm{~V}$ (versus RHE) was applied for $3 \mathrm{~min}$.

Electrochemical impedance spectroscopy measurement. Electrochemical impedance spectra measurements of $\mathrm{TiO}_{2}$-based photoanodes were performed with an electrochemical workstation (Model CHI760D, CH instruments, Inc., Austin, TX) with a three-electrode system, which was operated with the $\mathrm{TiO}_{2}$ nanotube array films as anode, platinum mesh as cathode and $\mathrm{Ag} / \mathrm{AgCl}$ as reference electrode. The spectra were measured at various forward bias voltages (from 0.15 to $0.5 \mathrm{~V}$ versus $\mathrm{RHE}$ ) in the frequency range of $0.1 \mathrm{~Hz}-1 \mathrm{MHz}$ with oscillation potential amplitudes of $10 \mathrm{mV}$ at room temperature.

XAFS measurement and data analysis. The Fe $K$-edge XAFS spectroscopy were recorded in the fluorescence mode at U7C beamline in the National Synchrotron Radiation Laboratory, China, 1W1B beamline of Beijing Synchrotron Radiation Facility, China, and BL14W1 beamline of Shanghai Synchrotron Radiation Facility, China. The acquired extended XAFS (EXAFS) data were processed according to the standard procedures using the ATHENA module implemented in the IFEFFIT software packages. The EXAFS $\chi(k)$ spectra were obtained by subtracting the postedge background from the overall absorption and then normalized with respect to the edge-jump step. Subsequently, $k^{3}$-weighted $\chi(k)$ data in the $k$-space ranging from 2.8 to $11.8 \AA^{-1}$ were Fourier transformed to real $(R)$ space using a hanning windows $\left(\mathrm{d} k=1.0 \AA^{-1}\right)$ to separate the EXAFS contributions from different coordination shells. 
Density functional theory calculation details. The first-principles density functional theory $+U$ calculations were performed using a plane wave basis set with the projector augmented plane-wave method ${ }^{39-42}$. The exchange-correlation interaction was described within the generalized gradient approximation in the form of PW91 (refs 43,44). The energy cutoff was set to $400 \mathrm{eV}$ and the atomic positions were allowed to relax until the energy and force were $<10^{-4} \mathrm{eV}$ and $10^{-3} \mathrm{eV} \AA^{-1}$, respectively. We used a $2 \times 2$ two-dimensional unit cells of anatase $\mathrm{TiO}_{2}(101)$ and $\mathrm{Fe}_{2} \mathrm{TiO}_{5}$ (110) consisting of a four-trilayer slab and a vacuum region of $12 \AA$ to mimic the $\mathrm{TiO}_{2}$ and $\mathrm{Fe}_{2} \mathrm{TiO}_{5}$ tube surfaces.

\section{References}

1. Gratzel, M. Photoelectrochemical cells. Nature 414, 338-344 (2001).

2. Hochbaum, A. I. \& Yang, P. D. Semiconductor nanowires for energy conversion. Chem. Rev. 110, 527-546 (2010).

3. Lewis, N. S. \& Nocera, D. G. Powering the planet: chemical challenges in solar energy utilization. Proc. Natl Acad. Sci. USA 103, 15729-15735 (2006).

4. Fujishima, A. \& Honda, K. Electrochemical photolysis of water at a semiconductor electrode. Nature 238, 37-38 (1972).

5. He, W. W. et al. Photogenerated charge carriers and reactive oxygen species in $\mathrm{ZnO} / \mathrm{Au}$ hybrid nanostructures with enhanced photocatalytic and antibacterial activity. J. Am. Chem. Soc. 136, 750-757 (2014).

6. Liu, L., Yu, P. Y., Chen, X. B., Mao, S. S. \& Shen, D. Z. Hydrogenation and disorder in engineered black $\mathrm{TiO}_{2}$. Phys. Rev. Lett. 111, 065505 (2013).

7. Thompson, T. L. \& Yates, J. T. Surface science studies of the photoactivation of $\mathrm{TiO}_{2}$-new photochemical processes. Chem. Rev. 106, 4428-4453 (2006).

8. Sivula, K., Le Formal, F. \& Grätzel, M. Solar water splitting: progress using hematite $\left(\alpha-\mathrm{Fe}_{2} \mathrm{O}_{3}\right)$ photoelectrodes. ChemSusChem 4, 432-449 (2011).

9. Macak, J. M., Tsuchiya, H. \& Schmuki, P. High-aspect-ratio $\mathrm{TiO}_{2}$ nanotubes by anodization of titanium. Angew. Chem. Int. Ed. 44, 2100-2102 (2005).

10. Shankar, K. et al. Recent advances in the use of $\mathrm{TiO}_{2}$ nanotube and nanowire arrays for oxidative photoelectrochemistry. J. Phys. Chem. C 113, 6327-6359 (2009).

11. Roy, P., Berger, S. \& Schmuki, P. $\mathrm{TiO}_{2}$ nanotubes: synthesis and applications. Angew. Chem. Int. Ed. 50, 2904-2939 (2011).

12. Liang, S. Z. et al. Improving photoelectrochemical water splitting activity of $\mathrm{TiO}_{2}$ nanotube arrays by tuning geometrical parameters. J. Phys. Chem. C 116, 9049-9053 (2012)

13. Yip, C. T. et al. Direct and seamless coupling of $\mathrm{TiO}_{2}$ nanotube photonic crystal to dye-sensitized solar cell: a single-step approach. Adv. Mater. 23, 5624-5628 (2011).

14. Guo, M. et al. Design and coupling of multifunctional $\mathrm{TiO}_{2}$ nanotube photonic crystal to nanocrystalline titania layer as semi-transparent photoanode for dyesensitized solar cell. Energy Environ. Sci. 5, 9881-9888 (2012).

15. Walter, M. G. et al. Solar water splitting cells. Chem. Rev. 110, 6446-6473 (2010).

16. Chen, X. \& Mao, S. S. Titanium dioxide nanomaterials: synthesis, properties, modifications, and applications. Chem. Rev. 107, 2891-2959 (2007).

17. Liu, G., Wang, L. Z., Yang, H. G., Cheng, H. M. \& Lu, G. Q. Titania-based photocatalysts-crystal growth, doping and heterostructuring. J. Mater. Chem. 20, 831-843 (2010)

18. Courtin, E. et al. New $\mathrm{Fe}_{2} \mathrm{TiO}_{5}$-based nanoheterostructured mesoporous photoanodes with improved visible light photoresponses. J. Mater. Chem. A 2, 6567-6577 (2014)

19. Li, Y. B. et al. Cobalt phosphate-modified barium-doped tantalum nitride nanorod photoanode with $1.5 \%$ solar energy conversion efficiency. Nat. Commun. 4, 2566 (2013).

20. Steinmiller, E. M. P. \& Choi, K. S. Photochemical deposition of cobalt-based oxygen evolving catalyst on a semiconductor photoanode for solar oxygen production. Proc. Natl Acad. Sci. USA 106, 20633-20636 (2009).

21. Zhu, C.-L. et al. $\mathrm{Fe}_{2} \mathrm{O}_{3} / \mathrm{TiO}_{2}$ tube-like nanostructures: synthesis, structural transformation and the enhanced sensing properties. ACS Appl. Mater. Interfaces 4, 665-671 (2012).

22. Sun, Z. H. et al. XAFS in dilute magnetic semiconductors. Dalton Trans. $\mathbf{4 2}$, 13779-13801 (2013)

23. LaTempa, T. J., Feng, X. J., Paulose, M. \& Grimes, C. A. Temperaturedependent growth of self-assembled hematite (alpha- $\mathrm{Fe}_{2} \mathrm{O}_{3}$ ) nanotube arrays: Rapid electrochemical synthesis and photoelectrochemical properties. J. Phys. Chem. C 113, 16293-16298 (2009).

24. Kim, T. W. \& Choi, K. S. Nanoporous $\mathrm{BiVO}_{4}$ photoanodes with dual-layer oxygen evolution catalysts for solar water splitting. Science 343, 990-994 (2014).

25. Shankar, K., Paulose, M., Mor, G. K., Varghese, O. K. \& Grimes, C. A. A study on the spectral photoresponse and photoelectrochemical properties of flameannealed titania nanotube-arrays. J. Phys. D Appl. Phys. 38, 3543-3549 (2005).
26. Tilley, S. D., Cornuz, M., Sivula, K. \& Gratzel, M. Light-induced water splitting with hematite: improved nanostructure and iridium oxide catalysis. Angew. Chem. Int. Ed. 49, 6405-6408 (2010).

27. Wang, G. et al. Hydrogen-treated $\mathrm{TiO}_{2}$ nanowire arrays for photoelectrochemical water splitting. Nano Lett. 11, 3026-3033 (2011).

28. Sun, Y. et al. Fabrication of flexible and freestanding zinc chalcogenide single layers. Nat. Commun. 3, 1057 (2012).

29. Butler, M. A. Photoelectrolysis and physical-properties of semiconducting electrode $\mathrm{WO}_{3}$. J. Appl. Phys. 48, 1914-1920 (1977).

30. Oregan, B. \& Gratzel, M. A low-cost, high-efficiency solar-cell based on dyesensitized colloidal $\mathrm{TiO}_{2}$ films. Nature 353, 737-740 (1991).

31. Katz, M. J. et al. Toward solar fuels: water splitting with sunlight and "rust"? Coord. Chem. Rev. 256, 2521-2529 (2012).

32. Lin, Y. J., Yuan, G. B., Sheehan, S., Zhou, S. \& Wang, D. W. Hematite-based solar water splitting: challenges and opportunities. Energy Environ. Sci. 4, 4862-4869 (2011).

33. Ginley, D. S. \& Butler, M. A. Photoelectrolysis of water using iron titanate anodes. J. Appl. Phys. 48, 2019-2021 (1977).

34. Bisquert, J. Theory of the impedance of electron diffusion and recombination in a thin layer. J. Phys. Chem. B 106, 325-333 (2002).

35. Mora-Sero, I. et al. Determination of carrier density of $\mathrm{ZnO}$ nanowires by electrochemical techniques. Appl. Phys. Lett. 89, 203117 (2006).

36. Zhong, D. K., Cornuz, M., Sivula, K., Grätzel, M. \& Gamelin, D. R. Photoassisted electrodeposition of cobalt-phosphate (Co-Pi) catalyst on hematite photoanodes for solar water oxidation. Energy Environ. Sci. 4, 1759 (2011),

37. Suntivich, J., May, K. J., Gasteiger, H. A., Goodenough, J. B. \& Shao-Horn, Y. A perovskite oxide optimized for oxygen evolution catalysis from molecular orbital principles. Science 334, 1383-1385 (2011).

38. Varghese, O. K., Paulose, M. \& Grimes, C. A. Long vertically aligned titania nanotubes on transparent conducting oxide for highly efficient solar cells. Nat Nanotechnol. 4, 592-597 (2009).

39. Blochl, P. E. Projector augmented-wave method. Phys. Rev. B 50, 17953-17979 (1994).

40. Kresse, G. \& Furthmuller, J. Efficiency of ab-initio total energy calculations for metals and semiconductors using a plane-wave basis set. Comput. Mater. Sci. 6, 15-50 (1996).

41. Kresse, G. \& Furthmuller, J. Efficient iterative schemes for ab initio total-energy calculations using a plane-wave basis set. Phys. Rev. B 54, 11169-11186 (1996).

42. Kohn, W. \& Sham, L. J. Self-consistent equations including exchange and correlation effects. Phys. Rev. 140, A1133-A1138 (1965).

43. Perdew, J. P. \& Wang, Y. Accurate and simple analytic representation of the electron-gas correlation-energy. Phys. Rev. B 45, 13244-13249 (1992).

44. Wang, Y. \& Perdew, J. P. Correlation hole of the spin-polarized electron-gas, with exact small-wave-vector and high-density scaling. Phys. Rev. B 44 13298-13307 (1991).

\section{Acknowledgements}

This work was supported by the National Natural Science Foundation of China (grant numbers 11135008, 11105151, U1332111, 11079004 and U1232132), the National Basic Research Program of China (2012CB825800) and the Foundation for Innovative Research Groups of the National Natural Science Foundation of China (11321503). We thank the National Synchrotron Radiation Laboratory, SSRF and BSRF for the synchrotron beamtime.

\section{Author contributions}

S.Q.W., Y.X., Z.Y.W., Q.H.L. and J.F.H. conceived the project. Y.X., Q.H.L., J.F.H., W.R.C., S.H. and Y.F.S. carried out the experiments. T.Y., Z.H.S., H.C., Y.J., F.C.H., Z.Y.P. and W.S.Y. analysed the experimental data. Z.Y.W., Q.H.L., Y.H.P. and Z.X performed the density functional theory calculations. All authors contributed to writing the manuscript.

\section{Additional information}

Supplementary Information accompanies this paper at http://www.nature.com/ naturecommunications

Competing financial interests: The authors declare no competing financial interests.

Reprints and permission information is available online at http://npg.nature.com/ reprintsandpermissions/

How to cite this article: $\mathrm{Liu}, \mathrm{Q}$.H. et al. Aligned $\mathrm{Fe}_{2} \mathrm{TiO}_{5}$-containing nanotube arrays with low onset potential for visible-light water oxidation. Nat. Commun. 5:5122 doi: 10.1038/ncomms6122 (2014). 